\title{
Desafios da inclusão do idoso no mercado de trabalho
} Challenges of elderly participation in the labor market

\author{
Karoline Silva Paolini'
}

\begin{abstract}
RESUMO |Contexto: Com o aumento da expectativa de vida, o envelhecimento se apresenta como um relevante problema social com repercussões na estrutura produtiva atual. Objetivo: $\mathrm{O}$ presente estudo teve por objetivo avaliar a contribuição do idoso para o mercado de trabalho brasileiro e as políticas públicas relacionadas. Métodos: Foi realizada uma revisão da literatura, com busca em duas bases de dados eletrônicas: Literatura Latino-Americana e do Caribe em Ciências da Saúde (LILACS) e Scientific Electronic Library Online (SciELO). A pesquisa foi realizada utilizando-se os seguintes Descritores em Ciências da Saúde (DeCS): idoso, mercado de trabalho, política pública, aposentadoria, trabalho, envelhecimento e saúde. Resultados: O trabalho é fonte de renda, satisfação pessoal e também é importante para a manutenção da qualidade de vida. Entretanto, os idosos usualmente precisam competir com os trabalhadores jovens, mais qualificados, além de enfrentarem a estigmatização social, o que dificulta a sua permanência no mercado de trabalho. As políticas vigentes ainda são insuficientes para incorporar a população mais idosa no processo produtivo. Conclusão: A implementação de políticas públicas voltadas para a integração dos idosos ao mercado de trabalho é mandatória, uma vez que a mão de obra global está envelhecendo rapidamente.
\end{abstract}

Palavras-chave I idoso; mercado de trabalho; aposentadoria; envelhecimento; políticas públicas.

ABSTRACT | Context: With life expectancy increasing, aging is a relevant social problem that affects the overall workforce. Objective: This study evaluates the contribution of the elderly in the Brazilian labor market and related public policies. Methods: A literature review was performed by searching in two electronic databases: Literatura Latino-Americana e do Caribe em Ciências da Saúde (LILACS) and Scientific Electronic Library Online (SciELO). The research was carried out using the following Health Sciences Descriptors (DeCS): elderly, job market, public policy, retirement, job, aging, and health. Results: Work is a source of income, personal satisfaction, and also is important for maintaining quality of life. However, the elderly usually must compete with younger, more skilled workers and cope with the social stigma. These factors make it difficult for older workers to remain in the labor market. Current policies are insufficient to incorporate the aging population in the workforce. Conclusion: The implementation of public policies aiming to integrate the elderly into the labor market is mandatory, since the global workforce is rapidly aging.

Keywords I aged; job market; retirement; aging; public policies. 


\section{INTRODUÇÃO}

A Organização Mundial de Saúde (OMS $)^{1}$ refere como pessoa idosa um limite de 60 anos ou mais de idade para os indivíduos. Tal definição corrobora a Lei $n^{\circ} 10.741$, de $1^{\circ}$ de outubro de 2003 , que dispõe sobre o Estatuto do Idoso e dá outras providências, no Título I, que engloba as disposições preliminares: "Art. $1^{\circ}$ : É instituído o Estatuto do Idoso, destinado a regular os direitos assegurados às pessoas com idade igual ou superior a 60 (sessenta) anos"2 (BRASIL, 2003, p.1). A criação dessa lei foi de grande significância, pois se tornou uma referência relevante para políticas que envolvem os idosos. Esse estatuto fez com que a terceira idade ganhasse mais notoriedade, uma vez que foram firmadas atribuições e garantias para essa geração, a fim de proporcionar maior segurança e, também, de tentar mudar a crendice que está instalada na sociedade, para que, com isso, haja diminuição do retraimento social imposto a eles, reação resultante do mundo capitalista atual ${ }^{3}$.

No Brasil, segundo dados do Instituto Brasileiro de Geografia e Estatística (IBGE) ${ }^{4}$, a transformação que está ocorrendo em relação à faixa etária da população representa uma das importantes pautas para debates, devido à reorganização estrutural que ocorre no país com o aumento da população idosa. Veras ${ }^{5}$, em 1988, já nos trazia os seguintes dados:

[... o Brasil ocupava no ano de 1950 o $16^{\circ}$ lugar no ranking mundial, com 2,2 milhões de idosos. Em 1985, essa população aumentou para 8,9 milhões, colocando o Brasil no $11^{\circ}$ lugar. No ano de 2025, o país deverá estar ocupando o sexto lugar no ranking, com uma população acima de sessenta anos estimada em 33,8 milhões. No período compreendido entre o ano de 1950 e 2025, a população brasileira terá aumentado cinco vezes, enquanto o número de idosos será quinze vezes maior (p. 382-3)

Em 2012, um estudo do $\mathrm{IBGE}^{6}$ revelou elevação no índice de envelhecimento da população: de $31,7 \%$, no ano de 2001, para 51,8\%, no ano de 2011. Esse estudo reportou também que as pessoas com 60 anos ou mais ocupavam $27 \%$ das vagas do mercado de trabalho. Espera-se que, devido ao envelhecimento populacional, elevem-se as chances de permanência desse trabalhador na atividade laboral, porém, pode haver necessidade de solicitar a aposentadoria antecipada, devido, por exemplo, a doenças próprias da idade avançada ${ }^{7}$. Com essa população adentrando o mercado de trabalho, é exigida uma adequação, tanto para o idoso quanto para as organizações, referente ao processo produtivo; com isso, esses trabalhadores podem enfrentar problemas relacionados à exclusão social ${ }^{8,9}$, visto que é uma situação difícil adaptação.

Diante disso, nas sociedades capitalistas do mundo globalizado, as relações de trabalho envolvendo trabalhadores idosos constituem um relevante problema que precisa ser amplamente discutido e equacionado, a fim de se diminuir a discriminação, a vulnerabilidade e a exclusão social às quais tais indivíduos estão expostos, bem como facilitar sua reinserção e permanência no mercado de trabalho. Ramos et al. ${ }^{8}$ afirmam:

Estudos evidenciam que cada vez mais as pessoas idosas precisam ou querem se manter no mundo do trabalho, situação que parece se distanciar do previsto para pessoas nessa faixa etária, pois a sociedade, de forma geral, espera que elas se encaminhem para a aposentadoria e para o afastamento do mundo laboral. (p. 507)

Essa perspectiva deveria permitir uma nova lógica, instituindo o retorno do idoso ao mercado de trabalho, uma vez que ele pode contribuir com as suas experiências adquiridas em anos de vivência e de vida laboral. $\mathrm{O}$ trabalho faz com que a pessoa esteja mais integrada com o mundo, possibilitando ao indivíduo obter e construir conhecimentos, desenvolver argumentos próprios para solução de problemas diários, usando meios que estão disponíveis ao seu redor para cumprir plenamente sua função de ser humano ${ }^{10}$, podendo, com isso, ter maior autonomia ao planejar o difícil seguimento para a aposentadoria ${ }^{11}$.

Sendo assim, para uma saída mais tardia do mercado de trabalho, é importante garantir ao trabalhador uma qualidade de vida adequada à sua idade ${ }^{12,13}$. Porém, para que isso ocorra, faz-se necessária a atenção dos governantes para uma gama de fatores e o planejamento de políticas específicas para esse segmento. Dessa maneira, o presente artigo teve o objetivo de discutir a participação do idoso no mercado de trabalho brasileiro e as políticas públicas relacionadas, envolvendo os temas de inclusão social e aposentadoria. 


\section{MÉTODOS}

Esta pesquisa consistiu em um levantamento bibliográfico, de caráter exploratório e descritivo. Realizou-se a busca em duas bases de dados eletrônicas: Literatura LatinoAmericana e do Caribe em Ciências da Saúde (LILACS) e Scientific Electronic Library Online (SciELO).

As consultas foram realizadas nos meses de julho e agosto do ano de 2014, utilizando-se os Descritores em Ciências da Saúde (DeCS), de forma combinada, sendo eles: (idoso) AND (mercado de trabalho); (idoso) AND (política pública); (idoso) AND (aposentadoria); (idoso) AND (trabalho); (envelhecimento) AND (idoso) AND (aposentadoria); (envelhecimento) AND (saúde).

Dentre os artigos recuperados com esses descritores, foram selecionados aqueles publicados na íntegra, em português e cujo título fosse referente à temática proposta, sendo excluídos os que apresentavam somente o resumo disponível ou estavam em idiomas diferentes do português. Cabe salientar que na busca encontraram-se artigos em língua estrangeira que abordavam o tema. Após a leitura dos resumos selecionados, excluíram-se as publicações que extrapolaram o contexto desta pesquisa, sendo escolhidas 29 para a análise.

Entretanto, três outras referências foram procuradas para enriquecer este manuscrito, sendo que duas delas foram encontradas nas bases SciELO e LILACS, por palavras contidas nos títulos, uma utilizando "exclusão e inclusão social", e a outra, "preparação para aposentadoria”, respectivamente; a terceira foi por busca ativa na Revista Brasileira de Medicina do Trabalho, para verificar se havia artigo recente publicado com tema aproximado.

Além desses artigos, consultaram-se leis e decretos relacionados ao tema da pesquisa, como a Constituição Federal do Brasil ${ }^{14}$, a Política Nacional do Idoso ${ }^{15}$ e o Estatuto do Idoso $^{2}$. Sites governamentais e outros relevantes - IBGE, OMS, Presidência da República, Instituto de Pesquisa Econômica Aplicada (Ipea) e da Previdência Social também foram consultados.

\section{RESULTADOS E DISCUSSÃO}

Os idosos começaram a ter maior evidência nas políticas públicas a partir da promulgação da Constituição
Federal de $1988^{14}$. A partir desse momento, diversos estudiosos começaram a debater sobre a proteção global a essa população, fazendo com que a atenção em relação ao envelhecimento fosse abordada e discutida por meio de várias vertentes, principalmente como um assunto complexo para a formação de políticas públicas ${ }^{16,17}$.

Algumas políticas nacionais, com destaque para a Política Nacional do Idoso ${ }^{15} \mathrm{e}$ o Estatuto do Idoso ${ }^{2}$, têm suma importância por suas contribuições. A Constituição Federal ${ }^{14}$ já nos trazia alguns fundamentos, principalmente os referentes à cidadania, à dignidade da pessoa humana e aos valores sociais do trabalho, ressaltando, em seu artigo $5^{\circ}$, que "todos são iguais perante a lei”, independentemente de idade, reprimindo qualquer tipo de discriminação. A Política Nacional do Idoso ${ }^{15}$ vem reafirmar o dever da família, da sociedade e do Estado em certificar os direitos do idoso, inclusive para agregá-lo na sociedade e permitir sua cooperação no meio onde vive, sem marginalização. Em 2003, o Estatuto do Idoso ${ }^{2}$ foi criado com o objetivo de legitimar os direitos da pessoa idosa já anteriormente assegurados, reforçando a participação e o convívio do idoso na sociedade, inclusive com outras gerações, por intermédio de meios simples e possíveis em diversas áreas, incluindo o trabalho. Essa lei ainda nos afirma que quem a desrespeitar sofrerá consequências, pois não será tolerado que seja cometido nenhum tipo de agressão contra o idoso. Além disso, aponta a importância da preparação para a aposentadoria, com intervenções pelo menos um ano antes do afastamento do serviço, para orientação e informação dos trabalhadores com relação ao planejamento dessa nova fase da vida.

Sob esse contexto, o envelhecer da população no Brasil encontra-se melindrado, pois, mesmo que esteja acontecendo o amparo progressivo relacionado aos idosos, encontramos vários deles ainda sendo ignorados pela sociedade, mostrando que a legislação vigente até então tem deixado a desejar, visto que o modo como são vistos e tratados pelo resto da população ainda não modificou ${ }^{18}$, fazendo com que continuem excluídos do contexto social.

Entretanto, o estudo realizado por Ramos et al. ${ }^{8}$ nos demonstra que o trabalhador idoso pode contribuir para o processo produtivo atual, devido às suas experiências e aos seus saberes oriundos da vida, adquiridos com o passar da idade, visto que o mercado de trabalho tem necessidade dessas trocas de conhecimentos. Como bem argumentam Rodrigues et al. ${ }^{19}$, o trabalho faz parte da construção da 
identidade da pessoa e, por isso, a ausência dele é um grande motivo de alterações emocionais no sujeito, pois é uma forma de incluir a pessoa em uma sociedade, criando círculos de amizades, o que é essencial à vida humana. Contudo, Alvarenga et al. ${ }^{20}$ afirmam que não necessariamente os aposentados ficarão inativos após sua saída da vida laboral, porém, é importante o indivíduo ter planejamento para realização de outras atividades paralelas ao trabalho, simplificando, assim, a confrontação da fase da velhice e da aposentadoria, possibilitando reorganizar sua nova condição de vida mais tranquilamente.

Podemos constatar que, apesar de se aposentarem, há idosos que permanecem trabalhando, mesmo que de modo informal, seja porque o baixo valor do benefício recebido necessita ser complementado, seja para que não se sintam inúteis e continuem ativos na sociedade, aumentando, assim, o bem-estar na velhice ${ }^{6,8,21}$. Dados do IBGE $^{6}$ demonstram que a informalidade está presente na população idosa em 71,7\% dos casos, mostrando a necessidade do mercado de trabalho se adequar, principalmente em números, gerando novos empregos para suprir a crescente demanda idosa no Brasil, população que muitas vezes tem baixa escolaridade e nível de qualificação inferior ao que o mercado capitalista tem exigido, porém, é passível de reciclagem ${ }^{22,23}$. Sendo assim, seguindo a abordagem da OMS para o envelhecimento ativo ${ }^{1}$, foi criado o Decreto Federal no 8.114, de 30 de setembro de 2013, que estabelece o Compromisso Nacional para o Envelhecimento Ativo, sendo uma de suas diretrizes, presentes no artigo $3^{\circ}$, a "ampliação de oportunidades para aprendizagem da pessoa idosa" ${ }^{24}$, a fim de tentar melhorar a valorização dessas pessoas.

Alvarenga et al..$^{20}$, em seu estudo, argumentam que a aposentadoria repercute na qualidade de vida por alterar subitamente o modo como o sujeito vai viver futuramente, pois as relações sociais, a renda e a visão de ser produtivo se modificam. Nesse contexto, Rodrigues et al. ${ }^{19}$ reforçam que podem ocorrer prejuízos no âmbito emocional, quando se apresentam quadros de ansiedade, depressão, angústia, dentre outros, afetando sobremaneira a qualidade de vida do trabalhador que está pensando em se aposentar, uma vez que vislumbra uma fase de mudanças na sua estrutura de vida. Para amenizar essa situação, é importante que o trabalhador vá se desligando das atividades laborais aos poucos e se envolva em outros interesses ${ }^{21}$, pois, ao diminuir o seu círculo de convívio e a quantidade de ações realizadas na sua rotina, pode haver comprometimento psicológico ${ }^{20}$, reduzindo, consequentemente, sua chance de atualização de forma geral.

Essa temática deve ser amplamente abordada e discutida, viabilizando a elaboração de políticas públicas que atendam às necessidades dos trabalhadores idosos; é importante que a aposentadoria não se apresente como um momento de tensão, e sim, que possa ser pensada ao longo da carreira, de forma que o trabalhador tenha como se planejar ${ }^{20,21}$ e encare a nova situação que se apresenta como a conclusão de uma fase e o início de outra, sem sentimento de decepção, arrependimentos e dúvidas. Como bem argumenta Zanelli ${ }^{21}$, a transição para a aposentadoria é um momento de mudança que deveria ser passado com menos estresse, proporcionando maior rendimento de forma saudável, voltado para atividades que geram satisfação, entusiasmo, distração e realização pessoal. $\mathrm{O}$ autor sugere ainda que esses indivíduos podem se beneficiar levando uma vida mais leve, com menos preocupações, mantendo sua saúde controlada, tendo hábitos saudáveis, melhorando, assim, sua expectativa e qualidade de vida.

A ausência que o trabalho gera, advinda da aposentadoria, pode ser considerada responsável pela redução da qualidade de vida do idoso. Sendo assim, é importante estimular que as pessoas tenham várias formas de participar da sociedade, seja trabalhando ou investindo na área social, dedicando-se a trabalhos voluntários, a atividades divertidas para si, religiosas ou culturais, ou mesmo voltadas para sua própria família ${ }^{1}$.

Entretanto, quando o idoso deseja voltar ao mundo laboral, precisa competir com concorrentes mais jovens, geralmente preferidos pelo mercado de trabalho devido ao seu maior grau de qualificação. O preconceito que existe com relação à terceira idade faz com que a sociedade naturalmente ignore o idoso, visto que uma das grandes dificuldades quanto à inclusão dessa parte da população no mercado de trabalho ocorre principalmente devido à valorização do jovem para a economia, distanciando os idosos do mundo laboral e associando-os ao final do ciclo produtivo só por causa da idade. Essa ideia deveria ser mudada por meio de incentivos para essa faixa etária continuar em atividade ${ }^{23}$, pois essa absorção da crescente força de trabalho é muito importante para diminuir o impacto dos gastos públicos ${ }^{25}$. Contudo, são poucas as chances que os indivíduos idosos têm de se atualizar e reciclar, dificultando sua permanência 
ou mesmo o seu retorno ao mercado de trabalho de forma digna. Em contrapartida, Zanelli ${ }^{21}$ e Kalache ${ }^{26}$ afirmam que os idosos poderiam, sim, contribuir para o mercado, por meio das suas experiências de vida, uma vez que, com mais discernimento e sabedoria, enfrentariam diversas situações cotidianas do mundo do trabalho com mais facilidade e, com isso, poderiam colaborar para o aumento da produtividade e a resolução de problemas.

Os empresários e governantes estão se deparando com problemas para manter essas pessoas idosas que estão no mercado de trabalho e desejam continuar trabalhando, mas existem medidas que auxiliariam nessa permanência, destacando-se a implantação de programas de capacitação continuada ${ }^{23}$, aumentando, assim, as chances de competição direta com os jovens, e a de promoção da saúde ${ }^{1}$, que visa incentivar uma vida mais saudável, podendo aumentar a longevidade. Por isso, o desenvolvimento de políticas públicas é extremamente importante para essa faixa etária, pois possibilita transformar os idosos em cidadãos com direitos protegidos por lei, ativos e com funcionalidade, fazendo com que essa fase da vida seja vivida da forma mais gratificante possível, além de contribuir para diminuir o dispêndio público com, por exemplo, assistência médica e pagamento de benefícios ${ }^{1}$.

Diante da atual tendência de crescimento do número de idosos na população, torna-se necessário criar e tornar reais, no sistema brasileiro, políticas públicas que protejam essa geração, assegurando a sobrevivência não só deles, mas também dos trabalhadores mais jovens de hoje, já que serão os idosos de amanhã. As empresas, devido à demanda populacional atual, ao contratarem pessoas para serem seus funcionários, devem pensar nas qualidades que as pessoas mais velhas têm a oferecer e sempre manter um sistema que garanta o conforto global dos trabalhadores, inclusive daqueles prestes a se aposentar ${ }^{27}$, porém, sem deixar de orientar e estimular os mais novos, visto que um dia irão também envelhecer.

Para que o processo de envelhecimento seja encarado com mais naturalidade, deve haver uma dinâmica entre a população idosa de hoje e a geração futura, pois é grande o desafio de garantir a inclusão plena do idoso na sociedade em geral e favorecer sua qualidade de vida ao longo dos anos. Sendo assim, é fundamental que o idoso possa ter a opção de escolher continuar ou não trabalhando, seja pela insuficiência da renda própria ou familiar, para continuar na carreira dos sonhos (tão árdua de ser conquistada), para obter descanso da vida laboral ou mesmo para realizar outros sonhos, como fazer cursos de culinária ou de línguas, visitar entes queridos, curtir netos, viajar, entre outros.

\section{CONCLUSÃO}

Devido aos desafios enfrentados pela nossa população (que está envelhecendo de forma veloz), como baixa qualificação, estigmatização da terceira idade, diminuição da capacidade funcional, características próprias do processo de envelhecimento, entre outros, faz-se necessária a implementação de políticas públicas mais específicas. Diante desse cenário, é imprescindível adequar o ambiente de trabalho e as atividades a serem realizadas às características típicas da velhice, proporcionando aos trabalhadores uma melhor qualidade de vida e adaptação à situação da aposentadoria, quando conquistada.

É desejável a realização, em diferentes regiões brasileiras, de estudos que envolvam a faixa populacional que está prestes a se aposentar, visando abordar qual o seu pensamento sobre o tema aposentadoria e sobre as novas situações que se apresentam nessa nova fase, a fim de demonstrar se tal população se prepara tanto emocional quanto economicamente.

\section{REFERÊNCIAS}

1. Organização Mundial de Saúde (OMS). Envelhecimento ativo: uma política de saúde. Brasília: Organização Pan-Americana da Saúde; 2005 [acesso em 2015 dez 1]. Disponível em: <http://bvsms.saude. gov.br/bvs/publicacoes/envelhecimento_ativo.pdf>

2. Brasil. Lei n 10.741 , de 01 de outubro de 2003. Dispõe sobre o Estatuto do Idoso e dá outras providências. Brasília: Diário Oficial da União; 2003.

3. Correa MR, FrançaSAM, Hashimoto F. Políticas públicas: a construção de imagens e sentidos para o envelhecimento humano. Estud Interdiscip Envelhec. 2010;15(2):219-38.
4. Instituto Brasileiro de Geografia e Estatística (IBGE). Estudos e Pesquisas. Informação Demográfica e Socioeconômica, número 25. Indicadores Sociodemográficos e de Saúde no Brasil. A Dinâmica Demográfica Brasileira e os Impactos nas Políticas Públicas. Rio de Janeiro: IBGE; 2009 [acesso em 05 ago. 2014]. Disponível em: <http://www.ibge.gov.br/english/estatistica/populacao/indic sociosaude/2009/indicsaude.pdf>

5. Veras RP. Considerações acerca de um jovem país que envelhece. Cad Saúde Pública. 1988;4(4):382-97. 
6. Instituto Brasileiro de Geografia e Estatística(IBGE). Estudose Pesquisas. Informação Demográfica e Socioeconômica, número 29. Síntese de Indicadores Sociais. Uma análise das condições de vida da população brasileira. Rio de Janeiro: IBGE; 2012 [acesso em 2014 jul 29]. Disponível em: <http://biblioteca.ibge.gov.br/visualizacao/livros/liv62715.pdf>

7. Camarano AA, Kanso S, Fernandes D. Menos jovens e mais idosos no mercado de trabalho? In: Camarano AA (Org.). Novo regime demográfico: uma nova relação entre população e desenvolvimento? Rio de Janeiro: Ipea; 2014. p. 377-406.

8. Ramos EL, Souza NVDO, Caldas CP. Qualidade de vida do idoso trabalhador. Rev Enferm UERJ. 2008;16(4):507-11.

9. Mendes MRSSB, Gusmão JL, Faro ACM, Leite RCBO. A situação social do idoso no Brasil: uma breve consideração. Acta Paul Enferm. 2005;18(4):422-6.

10. Borba AA, Lima HM. Exclusão e inclusão social nas sociedades modernas: um olhar sobre a situação em Portugal e na União Europeia. Serv Soc Soc. 2011;106:219-40.

11. Marangoni JFC, Mangabeira JA. Política integrada de atenção à saúde do servidor público do Distrito Federal: o programa de preparação para o período pós-carreia. Rev Bras Med Trab. 2014;12(1):8-15.

12. Batista MPP, Almeida MHM, Lancman S. Políticas públicas para a população idosa: uma revisão com ênfase nas ações de saúde. Rev Ter Ocup Univ. 2011;22(3):200-7.

13. Garrido R, Menezes PR. O Brasil está envelhecendo: boas e más notícias por uma perspectiva epidemiológica. Rev Bras Psiquiatr. 2002;24(Supl I):3-6.

14. Brasil. Constituição Federal (1988). Constituição da República Federativa do Brasil. Brasília: Senado Federal; 1988.

15. Brasil. Decreto no 1.948, de 03 de julho de 1996. Regulamenta a Lei no 8.842, de 4 de janeiro de 1994, que dispõe sobre a Política Nacional do Idoso, e dá outras providências. Brasília: Diário Oficial da União; 1996.

16. Andrade LM, Sena ELS, Pinheiro GML, Meira EC, Lira LSSP. Políticas públicas para pessoas idosas no Brasil: uma revisão integrativa. Ciênc Saúde Coletiva. 2013;18(12):3543-52.

17. Mendonça JMB, Pereira PAP. Envelhecimento, redes de serviços e controle democrático no capitalismo recente. Textos Contextos. 2013;12(1):142-51.
18. Sá MAAS. Política social, cuidados e cuidadores de idosos: Aproximações à realidade do Vale do Paraíba Paulista. In: Pimenta CAM, Alves CP (Orgs.). Políticas públicas \& desenvolvimento regional. Campina Grande: EDUEPB; 2010. p. 85-100 [acesso em 2014 maio 12]. Disponível em: SciELO Books <http://books. scielo.org>

19. Rodrigues M, Ayabe NH, Lunardelli MCF, Canêo LC. A preparação para a aposentadoria: o papel do psicólogo frente a essa questão. Rev Bras Orientac Prof. 2005;6(1):53-62.

20. Alvarenga LN, Kiyan L, Bitencourt B, Wanderley KS. Repercussões da aposentadoria na qualidade de vida do idoso. Rev Esc Enferm USP. 2009;43(4):796-802.

21. Zanelli JC. Processos Psicossociais, bem-estar e estresse na aposentadoria. Rev Psicol Organ Trab. 2012;12(3):329-40.

22. Wajnman S, Oliveira AM, Oliveira EL. Os idosos no mercado de trabalho: tendências e conseqüências. In: Camarano AA (Org.). Os novos idosos brasileiros: muito além dos 60 ? Rio de Janeiro: Ipea; 2004. p. 453-79.

23. Lopes APN, Burgardt VM. Idoso: um perfil de alunos na EJA e no mercado de trabalho. Estud Interdiscipl Envelhec. 2013;18(2):311-30.

24. Brasil. Decreto no 8.114, de 30 de setembro de 2013. Estabelece o Compromisso Nacional para o Envelhecimento Ativo e institui Comissão Interministerial para monitorar e avaliar ações em seu âmbito e promover a articulação de órgãos e entidades públicos envolvidos em sua implementação. Brasília: Diário Oficial da União; 2013.

25. Batista AS, Jaccoud LB, Aquino LA, El-Moor PD. Envelhecimento e dependência: desafios para a Organização da Proteção Social. Brasília: Ministério da Previdência Social; 2008. 160 p.

26. Kalache A. O mundo envelhece: é imperativo criar um pacto de solidariedade social. Ciênc Saúde Coletiva. 2008;13(4):1107-11.

27. França LHFP, Soares DHP. Preparação para a aposentadoria como parte da educação ao longo da vida. Psicol Cienc Prof. 2009;29(4):738-51.

Endereço para correspondência: Karoline Silva Paolini - Rua Silveira Martins, 110/315 - Flamengo - CEP: 22221-000 - Rio de Janeiro (RJ), Brasil -

E-mail: karolinesilva5@hotmail.com 